\title{
Association between the Characteristics of Pre-Surgery Vascular Ultrasonography and the Successful Arterio-Venous Fistula Shunt Surgery as Hemodialysis Access to Patients with Kidney Disease Stage V
}

\author{
Nurwanto $^{1}$, Prijambodo ${ }^{1}$, Tri Wulan handarini ${ }^{1}$, Windhu Purnomo ${ }^{2}$ \\ ${ }^{1}$ Departement of Radiology, Faculty of Medicine, Universitas Airlangga, Dr. Soetomo Teaching Hospital, \\ Surabaya, Indonesia, ${ }^{2}$ Department of Statistics and Population, Faculty of Public Health, Universitas Airlangga,
} Surabaya, Indonesia

\begin{abstract}
Background: The failure rate of arterio-venous fistula shunt for hemodialysis access in patients with chronic kidney disease is high. Vascular characteristic is one of the important indicators in successful operation.

Objective: To determine the association between pre-surgery vascular ultrasonography characteristics and the successful arterio-venous fistula shunt surgery as hemodialysis access in patients with chronic kidney disease stage $\mathrm{V}$.

Methods: This study used descriptive analytic studies to determine the relationship between pre-operative vascular ultrasonography characteristics, such as arteries (diameter, velocity, thickness of intima-media tunica) and vein (diameter, velocity, depth) with successful arterio-venous fistula shunt surgery that evaluated in four week post-surgery in patients with chronic kidney disease stage V.

Results: Eighteen samples that consisted of $27.8 \%$ female and $72.2 \%$ male were enrolled in this study. The most surgery location was vascular radio-cephalic of 13 samples (72.2\%). Statistical analysis used was Mann-Whitney U Test. There was no significant correlation between arterial diameter $(\mathrm{p}=0.127)$, venous diameter of AVFs $(p=1.000)$, arterial velocity $(p=0.721)$, velocity vein $(p=0.721)$, intima media tunica thickness $(p=0.721)$, and venous depth $(p=0.192)$ with successful arterio-venous fistula shunt surgery.

Conclusion: There was no significant correlation between diameter, thickness of intima media tunica, and arterial velocity as well as diameter, velocity and venous depth with successful arterio-venous fistula shunt surgery.
\end{abstract}

Keywords: Vascular, Ultrasonography Examination, Arterio-venous Fistula

\section{Introduction}

In patients with catheterization or patients requiring venous access, doppler ultrasonography of upper limb

\section{Corresponding author:}

Prijambodo

Department of Radiology, Faculty of Medicine, Universitas Airlangga, Dr. Soetomo Teaching Hospital, Surabaya, Indonesia 60131,Phone: (+62) 85850083032 E-mail: prijambodoradiologyunair@gmail.com venous was required for identifying suitable vascular to access. This vascular was screened for the possibility of central stenosis or occlusion. It was recommended to use pre-surgery ultrasonography in patients who had experienced previous central venous access associated with deep venous thrombosis in order to assess central or occlusion stenosis ${ }^{1}$. SG of vascular mapping prior to placement of hemodialysis access was a prescribed procedure. Pre-surgery sonographic mapping prior to placement of hemodialysis access may change surgical management, with an increasing number of AVF and the 
possibility of an increase in the most functional vascular selection ${ }^{2}$.

Chronic Kidney Disease (CKD) is the final stage of renal failure with the Glomerular Filtration Rate (GFR) of $<15 \mathrm{ml} /$ minute $^{3}$. Causes of CKD are diabetes mellitus, hypertension, renal ischemia, toxic substances, obstruction, autoimmune disease and renal infiltration ${ }^{4}$. Data from The United States Renal Data System (USRDS 2013) showed the prevalence rate of people with chronic kidney disease in the United States (2011) of 1,901 every a million population. Treatment of EndStage Organ Failure in Canada (2000-2009) reported that nearly 38,000 Canadians lived with chronic renal failure and has increased almost three times from 1990. 59\% of those number $(22,300)$ have undergone hemodialysis and 3000 patients have been waiting kidney transplant ${ }^{5}$. Meanwhile, Indonesia reached 200-250 cases every a million populations every year.

Hemodialysis requires a well-functioning vascular access. The best type of vascular access is the ArterioVena Fistula (AVF). Making AVF is associated with failure rates and complications. The most common causes of AVF dysfunction are non-maturation, thrombosis, and stenosis, thus most cases of previous stenosis lead to disruption of blood flow. Function and morphological of USG was used for AVF dialysis that affects the risk of vascular access dysfunction ${ }^{6}$.

Vascular access is ideal if it can be used for long periods of time as access to blood circulation with minimal complications. Arterio-venous fistula (AVF shunt) is the most ideal access of all available hemodialysis access. If AVF shunt is successful then it can be used for long periods with low thrombosis and infection rates, without much interventions and low costs ${ }^{7}$. AVF-shunt cubiti operation is an AVF operation technique. AVF shunt operation is the first choice in AVF technique whereas; AVF cubiti is the second choice. However, the failure rate of both techniques remains high $^{8}$. There remains a high failure rate of fistula arterio-venous shunt installation in patients with chronic kidney disease. Complications of vascular access are the common cause of failure and hospitalization in dialysis patients. Limited data to comprehend the complications of arterio-venous fistula especially stenosis and thrombosis also inhibit the success of arterio-venous fistula techniques.

Based on the research described above, it is necessary to examine the association between the characteristics of arterial ultrasonography (USG) and pre-surgery vein with the successful AVF shunt surgery, thus the characteristic factor of arteries and veins that affect the success of shunt AVF operation could be recognized. Therefore, the authors aimed to determine the association between pre-surgery vascular ultrasonography characteristics and the successful arterio-venous fistula shunt surgery as hemodialysis access in patients with chronic kidney disease stage $\mathrm{V}$.

\section{Method}

This study was a retro-prospective longitudinal with the observational design. We used a consecutive sampling technique to the patients of chronic kidney disease stage $\mathrm{V}$. The inclusion criteria were patients aged $>18$ years, undergoing routine hemodialysis or will be planned of routine hemodialysis, had been performed operation of AVF shunt in Dr. Soetomo General Hospital Surabaya from January to March 2015.

Patients with chronic kidney disease stage V, which will be operated with AVF shunt as a hemodialysis vascular access, were performed USG examination using high-resolution USG Hitachi equipped with linear probes (7-10 MHz) in Radio Diagnostic Unit of Dr. Soetomo General Hospital Surabaya. The scan was performed in recumbent position with the arm down of 45 degrees from the body.

The USG results were recorded and then analyzed statistically. Descriptive analysis was conducted to obtain the characteristic of the sample. Normality test using Kolmogorov-Smirnov test was performed prior to analyze the correlation between pre-surgery vascular ultrasonography characteristics and the successful arterio-venous fistula shunt surgery as hemodialysis access. Mann-Whitney U Test was used with confidence interval of $95 \%$ and $p$ value $<0.05$. The analysis was conducted with SPSS software. The study protocol was approved by Dr. Soetomo Teaching Hospital.

\section{Results}

\section{Characteristics of Subjects}

This study obtained 16 CKD patients who will be performed AVFs surgery. Patients consisted of 12 male and 4 female with age ranged from 33 to 62 years. All patients had a vascular duplex USG examination at the location that will be performed, however two patients performed two surgeries at different sites due to the 
failure on the first surgery thus we obtained 18 samples. The youngest age of the patient was 33 years old and the oldest was 62 years.

\section{Distribution of Subjects by Age}

The most age group in eighteen samples of study that will be performed AVFs surgery was 51-60 years of 9 patients $(50 \%)$. The age group of $<40$ years was 2 patients (11.1\%), 41-50 years old of 6 patients $(33.3 \%)$, and $>60$ years of 5 patients $(5.6 \%)$ (Table 1$)$.

Table 1. Distribution of Samples by Age

\begin{tabular}{|l|l|l|}
\hline Age & Frequency & Percentage (\%) \\
\hline & & \\
$<40$ years & 2 & 11.1 \\
$41-50$ years & 6 & 33.3 \\
$51-60$ years & 9 & 50.0 \\
$>60$ years & 1 & 5.6 \\
Total & 18 & 100.0 \\
& & \\
\hline
\end{tabular}

Distribution of Subjects by Sex

We found 13 male (72.2\%) and 5 female (27.8\%). CGK patients who had pre-surgery vascular USG of AVFs were more prevalent in males than females with a ratio of $3: 1$

\section{Distribution of Subjects by AVFs Location}

Subjects who had performed AVFs surgery were 5 patients $(27.8 \%)$ in the inferior fossa cubiti brachio-cephalic blood vessels and $13(72.2 \%)$ subjects who had performed surgery on arterial radio-cephalic arteries.

\section{Characteristics of Vascular Samples}

Table 2. Characteristics of Vascular Samples

\begin{tabular}{|l|l|l|l|l|l|l|}
\hline \multicolumn{2}{|l|}{} & Mean & Median & SD & Minimum & Maximum \\
\hline \multirow{4}{*}{ Diameter (mm) } & a.Brachialis & 3.2 & 3.2 & 0.2 & 2.9 & 3.5 \\
& a.Radialis & 2.1 & 2.2 & 0.5 & 1.2 & 2.8 \\
& v.Cephalica & 1.6 & 1.5 & 0.8 & 0.6 & 3.5 \\
\hline \multirow{2}{*}{$\begin{array}{l}\text { Tunica intima Media } \\
(\mathrm{mm})\end{array}$} & a.Brachialis & 0.4 & 0.4 & 0.07 & 0.3 & 0.5 \\
& a.Radialis & 0.4 & 0.3 & 0.1 & 0.2 & 0.6 \\
\hline & & & & & & \\
Velocity $(\mathrm{cm} / \mathrm{s})$ & a.Brachialis & 51.8 & 50.5 & 16.3 & 28.4 & 74.0 \\
& a.Radialis & 52.1 & 47.3 & 15.4 & 27.8 & 73.8 \\
& v.Cephalica & 7.1 & 7.2 & 2.7 & 3.2 & 12.3 \\
\hline Depth $(\mathrm{mm})$ & v.Cephalica & 2.8 & 2.6 & 0.9 & 1.8 & 4.4 \\
\hline
\end{tabular}

Table 2 showed the vascular characteristics of the sample consisted of the brachial artery, radial artery, and cephalica vein as the vascular access of the AVFs surgery. We found five samples of brachial artery, 13 samples of radial artery, and 18 samples of venous cephalica. 
Distribution of Subjects Based on Successful AVFs Surgery

Eight-teen samples have been performed AVFs operation which resulted in $14(77.8 \%)$ successful operations and $4(22.2 \%)$ failed operations.

\section{Results Analysis}

The Correlation of Artery Diameter with AVFs Operating Results

Successful AVFs surgery was 14 (77.2\%) samples with a minimum diameter of $1.5 \mathrm{~mm}$, a maximum of 3.5 $\mathrm{mm}$, a median of $2.4 \mathrm{~mm}$ and a mean diameter of 2.5 $\mathrm{mm}$ and a standard deviation of 0.6. Meanwhile, failure surgery was $4(22.8 \%)$ samples with a minimum diameter of $1.2 \mathrm{~mm}$, maximum of $2.6 \mathrm{~mm}$, a median of $1.8 \mathrm{~mm}$ and mean diameter of $1.8 \mathrm{~mm}$ and standard deviation of 0.7. The statistical test showed no association between arterial diameter with AVFs surgery results $(p=0.127)$.

\section{The Correlation of Vena Diameter with AVFs Operating Results}

From 18 samples of the study, $14(77.2 \%)$ of cephalica vein samples from successful AVFs surgery had a minimum diameter of $0.6 \mathrm{~mm}$, a maximum of 3.5 $\mathrm{mm}$, a median of $1.6 \mathrm{~mm}$ and a mean diameter of 1.6 $\mathrm{mm}$ and a standard deviation of 0.7 . Whereas, 4 (22.8\%) of cephalica vein samples from failed surgery had a minimum diameter of $1 \mathrm{~mm}$, a maximum of $3.4 \mathrm{~mm}$, a median of $1.4 \mathrm{~mm}$, a mean of $1.8 \mathrm{~mm}$ diameter and a standard deviation of 1.1. The statistical test showed no association between vein diameter and result of AVFs surgery $(p=1.000)$.

\section{The Correlation of Artery Velocity with AVFs Operating Results}

From 14 samples of brachial artery and radial artery from successful AVF operation had a minimum velocity of $27.8 \mathrm{~cm} / \mathrm{s}$, a maximum of $74 \mathrm{~cm} / \mathrm{s}$, a median of 50 $\mathrm{cm} / \mathrm{s}$ and a mean of 50.9. Meanwhile, 4 samples from failed operation had a minimum velocity of $40 \mathrm{~cm} / \mathrm{s}$, maximum of $71.3 \mathrm{~cm} / \mathrm{s}$, median of $56.7 \mathrm{~mm}$, mean of $56.2 \mathrm{~cm} / \mathrm{s}$ and standard deviation of 15.5 . Statistical tests showed that there was no association between arterial velocity and successful AVFs surgery $(p=0.721)$.

\section{The Correlation of Vena Cephalica Velocity with AVFs Operating Results}

From 14 venous cephalica samples had a minimum velocity of $3.6 \mathrm{~cm} / \mathrm{s}$, a maximum of $12.3 \mathrm{~cm} / \mathrm{s}$, median of $7.2 \mathrm{~cm} / \mathrm{s}$ and mean of $7.3 \mathrm{~cm} / \mathrm{s}$ and standard deviation of 2.6. While the 4 sample venous cephalica from the failed operation had a minimum velocity of $3.2 \mathrm{~cm} / \mathrm{s}$, maximum of $10 \mathrm{~cm} / \mathrm{s}$, median of $6.1 \mathrm{~cm} / \mathrm{s}$, mean of 6.4 $\mathrm{cm} / \mathrm{s}$ and standard deviation of 3.3. The statistical test showed no association between velocity of venous and successful operation of AVFs $(p=0.721)$

\section{The Correlation of Thickness of Tunica Intima} Media Artery with AVFs Operating Results

The intima media tunica thickness of 14 (77.2\%) successful surgeries had a minimum diameter of $0.2 \mathrm{~mm}$, a maximum of $0.6 \mathrm{~mm}$, a median of $0.4 \mathrm{~mm}$, a mean of $0.4 \mathrm{~mm}$ and a standard deviation of 0.15 . Whereas, 4 (22.8\%) samples from failed operation had a minimum intima media tunica thickness of $0.3 \mathrm{~mm}$, maximum of $0.4 \mathrm{~mm}$, median of $0.4 \mathrm{~mm}$, mean of $0.4 \mathrm{~mm}$ and standard deviation of 0.06 . The statistical test showed no correlation between intima media tunica thickness with successful AVFs surgery $(p=0.721)$.

\section{The Correlation of Depth of Vein with AVFs Operating Results}

We found $14(77.2 \%)$ samples from successful AVFs operations with a minimum depth of $1.8 \mathrm{~mm}$, a maximum of $4.1 \mathrm{~mm}$, a median of $2.5 \mathrm{~mm}$ and a mean of $2.6 \mathrm{~mm}$. While 4 (22.8\%) failed samples had a minimum depth of $2.2 \mathrm{~mm}$, maximum $4.4 \mathrm{~mm}$, median $3.4 \mathrm{~mm}$ and mean of $3.4 \mathrm{~mm}$. The statistical test showed no association between cephalica vein depth with successful AVFs surgery $(p=0.192)$.

\section{Discussion}

Doppler USG of vascular provided qualitative and quantitative data on arterial and venous systems prior to the establishment of AVFs. Doppler USG techniques could identify which veins are often missed on clinical examination. This approach was particularly useful in patients with DM and the elderly due to arterial narrowing and a relatively common classification in patients with CKD. Therefore, arterial evaluation should be performed to determine patency, morphology of capillary walls, diameter and anatomy, while venous evaluation was performed to determine patency, diameter, and depth ${ }^{9}$.

The study obtained 18 samples consisted of 5 females (27.8\%) and 13 males (72.2\%). The most common age 
group was 51-60 years by 8 people (50\%) followed by age group of $41-50$ years by 5 people $(31.25 \%)$. This was similar the epidemiological data of CKD patients who underwent hemodialysis that it happened more in male than female and often occurred at the age of 40-60 years old ${ }^{10}$.

The diameter of the artery in this study was smaller than the mean diameter of the brachial artery in other studies by $4.31 \pm 0.77 \mathrm{~mm}$ and the mean of radial artery by $2.325 \pm 0.4 \mathrm{~mm}^{11,12}$. The velocity of the brachial and radial arteries in this study was lower than the normal value of Brachial artery by $50-100 \mathrm{~cm} / \mathrm{s}$ and Radial artery by $40-90 \mathrm{~cm} / \mathrm{s}^{13}$.

There was no significant correlation between arterial diameter and AVFs operation results $(p=0.127)$; the mean diameter of successful surgery was $2.5 \mathrm{~mm}$ and the failed surgery had a mean of $1.8 \mathrm{~mm}$. The successful AVFs surgery were linked to a minimum diameter of artery by $2 \mathrm{~mm}^{9}$.

The statistical test showed no correlation between the thickness of tunica intima-media with the successful operation of AVFs ( $p=0.721$ ). Moreover, there was no association between arterial velocity and AVFs surgery results $(\mathrm{p}=0.721)$; a mean velocity of successful surgery was $50.9 \mathrm{~cm} / \mathrm{s}$ and a mean velocity of failed surgery was $56.2 \mathrm{~cm} / \mathrm{s}$.

Statistics tests showed no association between vein diameter and AVFs operation results $(p=1,000)$. The mean of venous diameter on successful AVFs was $1.6 \mathrm{~mm}$ and failed AVFs had a mean diameter of 1.8 $\mathrm{mm}$. The results were different to a study by Silva who reported successful surgery of AVFs had a minimum diameter of $2.5 \mathrm{~mm}$ and she recommended a diameter of at least $3 \mathrm{~mm}$ for AVFs surgery ${ }^{9}$.

The larger diameter of the cephalic vein was associated with lower resistance of blood flow and increased blood flow rate in the fistulas. The larger diameter of the cephalic vein was also associated with low risk of thrombotic, post-inflammatory lesions, and morphological vein wall abnormalities. This results confirmed the importance of pre-surgery vascular assessment prior to the establishment of AVFs ${ }^{6}$. Previous studies recommended to use an artery diameter of at least $2.5 \mathrm{~mm}$ and a vein diameter of at least $2 \mathrm{~mm}$ to establish the AVFs. However, there was no agreement on the threshold value of minimal diameter of the artery or vein that should not be used to form anastomosis. Therefore, there was also a medical center which required an AVFs procedure with a diameter of less than $1.5 \mathrm{~mm}^{6}$.

This study also showed that there was no association between venocity of venous and successful AVFs surgery $(p=0.721)$; the mean velocity of the successful operation was $7.3 \mathrm{~m} / \mathrm{s}$ and the mean velocity of failed operation was $6.4 \mathrm{~cm} / \mathrm{s}$. Moreover, there was no association between cephalica vein depth with successful AVFs surgery ( $p=0.192)$. The mean venous depth of successful operation was $2.6 \mathrm{~mm}$ and the failed operation had a mean vein depth of $3.3 \mathrm{~mm}$. This study showed that successful AVFs surgery had higher velocity rates and a shallower cephalic vein depth.

\section{Conclusion}

There was no significant correlation between diameter, thickness of intima media tunica, and arterial velocity as well as diameter, velocity and venous depth with successful arterio-venous fistula shunt surgery.

Ethical Clearance: The present study was carried out in accordance with the research principles. This study implemented the basic principle ethics of respect, beneficence, nonmaleficence, and justice.

Conflict of Interest: There is no report of conflict of interest involved with this study so far.

Source of Funding: This study is funded by authors' fund only without external funds or donation.

\section{References}

1. Povoski SP, Zaman SA. Selective use of preoperative venous duplex ultrasound and intraoperative venography for central venous access device placement in cancer patients. Ann Surg Oncol. 2002;9(5):493-9.

2. Weber TM, Lockhart ME, Robbin ML. Upper extremity venous Doppler ultrasound. Radiol Clin North Am. 2007;45(3):513-24.

3. Erwinsyah E. Hubungan antara Quick Of Blood (Qb) dengan Penurunan Kadar Ureum dan Kreatinin Plasma pada Pasien Ckd yang Menjalani Hemodialisis di RSUD Raden Mattaher Jambi. J Ilm Univ Batanghari Jambi. 2017;14(2):97-104.

4. Snively CS, Gutierrez C. Chronic kidney disease: prevention and treatment of common complications. Am Fam Physician. 2004;70(10):1921-8.

5. Corrigan R. The experience of the older adult with 
end-stage renal disease on hemodialysis. 2011.

6. Bojakowski K, Gorczyca-Wiśniewska E, Szatkowski M, Walecki J, Andziak P. Preoperative ultrasonographic examination of the radial artery and the cephalic vein and risks of dialysis arteriovenous fistula dysfunction. Polish $\mathrm{J}$ Radiol. 2010;75(1):7.

7. Hammes M. Hemodialysis Access: The Fistula. In: Technical Problems in Patients on Hemodialysis. InTech; 2011.

8. Initiative NKF-DOQ. Clinical practice guidelines for vascular access. Am J Kidney Dis. 2006;48(1):S176-276.

9. Aishwarya KC, Srinath MG, Desai SC, Kumar A, Chandrashekar AR, AG GG. Value of preoperative sonographic vascular evaluation of haemodialysis access in upperlimb. J Clin diagnostic Res JCDR. 2014;8(12):RC06.
10. Coresh J, Astor BC, Greene T, Eknoyan G, Levey AS. Prevalence of chronic kidney disease and decreased kidney function in the adult US population: Third National Health and Nutrition Examination Survey. Am J kidney Dis. 2003;41(1):1-12.

11. King CM. Brachial artery dimensions, flowmediated reactivity and physical function in older adults. 2004;

12. Beniwal S, Bhargava K, Kausik SK. Size of distal radial and distal ulnar arteries in adults of southern Rajasthan and their implications for percutaneous coronary interventions. Indian Heart J. 2014;66(5):506-9.

13. Myers K, Clough AM. Practical Vascular Ultrasound: An Illustrated Guide. CRC Press; 2014. 